\title{
Teoría queer en el contexto español. Reflexiones desde el feminismo
}

\author{
Queer theory in the Spanish context. \\ Reflections from feminism
}

LUISA POSADA KUBISSA*

\begin{abstract}
Resumen: La teoría queer, desarrollada especialmente en Estado Unidos a inicios de los años 90, ha tenido también su impacto en los círculos de pensamiento del contexto español a partir de esas fechas. Se trata con esta teoría de poner de relieve la vinculación entre el sexo biológico, el rol social del género y el deseo sexual. Nos centraremos en algunas aportaciones en esta línea en el Estado español, para pasar finalmente a hacer algunas reflexiones por las que consideramos aquí que estos análisis no pueden ser interpretados como una suerte de discurso que viniera a sustituir al feminismo.

Palabras clave: Teoría queer, feminismo, sexualidad, género, identidad, deconstrucción.
\end{abstract}

\begin{abstract}
Queer theory, specially developed in the United States at the beginning of the 1990s, has also had its impact in the circles of thought of the Spanish context from those dates. This theory tries to highlight the link between biological sex, social gender role and sexual desire. We will focus on some contributions in this line in the Spanish State, and we will finish making some reflections in which we consider that queer theory cannot be interpreted as a kind of speech that comes to replace feminism.
\end{abstract}

Key words: Queer Theory, feminism, sexuality, gender, identity, deconstruction.

\section{Notas sobre la teoría queer}

La teoría queer parte, como el constructivismo feminista contemporáneo, de la tesis según la cual la identidad genérica y la sexual no constituyen un dato natural, sino que ambas son construidas por procesos culturales y sociales. Tomando como precedentes teóricos el pensamiento de la deconstrucción, el post-estructuralismo y los estudios de género, esta teoría se propone analizar las identidades sexuales, las formas de poder y las normas con la mirada puesta en su deconstrucción. Entre sus raíces teóricas principales reclama las apor-

Fecha de recepción: 08/01/2014. Fecha de aceptación: 11/08/2014.

* Profesora Titular de Filosofía de la Universidad Complutense de Madrid: lposada@filos.ucm.es. Líneas de investigación: filosofía y feminismo, teoría crítica feminista, Ilustración, Kant, epistemología. «Sobre Kant, Putnam y el realismo interno», Anales del Seminario de Historia de la Filosofía, 29/1 (2012); «Argumentos y contra-argumentos para un debate. Sobre trata y prostitución», Ex Aequo, Revista da Associaçao Portuguesa de Estudos sobre as Mulheres, 26 (2013). 
taciones de Michel Foucault (Foucault, 1976), Judith Butler (Butler, 1990), Eve Kosofsky Sedgwick (Sedgwick, 1990) y Michael Warner (Warner, 1993).

La deconstrucción de la sexualidad cobra en esta teoría relevancia primordial, a partir de la cual aborda también aspectos de la cultura relacionados con los géneros y con los roles genéricos. La definición de qué sea la teoría queer ya es de por sí problemática: teniendo en cuenta qué se entiende por teoría «(...) es evidente que utilizar la palabra 'teoría' para referirse a los estudios queer es bastante inapropiado», puesto que « lo que llamamos teoría queer no es un corpus organizado de enunciados, ni tiene ninguna pretensión de cientificidad, ni aspira a dar cuenta de un objeto claramente definido, es decir, no es propiamente hablando "una teoría"» (Sáez, 2008, 126-7). Pero dejando de lado esta imprecisión conceptual del término «teoría», lo cierto es que «(...) queer es más que la suma de gays y lesbianas, incluye a éstos y a muchas otras figuras identitarias construidas en ese espacio marginal (transexuales, transgénero, bisexuales, etc.) a la vez que se abre a la inclusión de todas aquéllas que puedan proliferar en su seno» (Córdoba García, 22).

Se entienda como se entienda, la utilización de la teoría queer en las disciplinas científico-académicas ha dado lugar a los denominados «estudios queer». Núcleo central de estos estudios es la filosofía del lenguaje, en particular la teoría de los actos de habla, que juega un papel relevante ya en relación al propio término queer, puesto que el mismo implica una resignificación de esta expresión que la rescata de su uso despectivo y busca situarla en nuevo contexto valorativo. Queer se asocia tradicionalmente a homosexual, en una connotación negativa que tendría como traducción literal algo «torcido» (Llamas, 1998), «raro», «dudoso», etc. Los activistas y teóricos queer han resignificado el término para apropiárselo en sentido positivo: se trata de una palabra «cuyo significado y contexto se han visto (y se siguen viendo) llenos de negatividad utilizada a la vez como humillación e insulto, (que) se convierte en la década de los ochenta en el término descriptivo del orgullo de una identidad homosexual y, más adelante, en la etiqueta académica utilizada por los más prestigiosos eruditos en materia de género, siendo rescatada de dicho contexto y relanzada como concepto positivo y teórico, dado que este término dará cobijo a todo un marco de estudio sobre sexualidad no normativa» (Ceballos Muñoz, 168).

Ya la antropóloga Margaret Mead puso de manifiesto la variablidad de los roles genéricos, lo que sin duda apunta a su carácter no natural. Y más tarde será el filósofo Michel Foucault quien analice cómo el pensamiento del binarismo sexual, y su concepción sobre sexualidad y homosexualidad, responden a un constructo, a un dispositivo social, cultural y epistemológico, que luego viene a significarse y a imponerse como dato natural. Y será en particular Judith Butler quien extraiga las consecuencias de estos análisis para el caso del sexo-género, concluyendo en el carácter construido del segundo pero también del primero: «En este sentido, lo que constituye el carácter fijo del cuerpo, sus contornos, sus movimientos, será plenamente material, pero la materialidad deberá reconcebirse como el efecto del poder, como el efecto más productivo del poder. Y no habrá modo de interpretar el "género" como una construcción cultural que se impone sobre la superficie de la materia, entendida o bien como "el cuerpo" o bien como su sexo dado. Antes bien, una vez que se entiende el "sexo" mismo en su normatividad, la materialidad del cuerpo ya no puede concebirse independientemente de la materialidad de esa norma reguladora» (Butler, 2002: 18-19). 
La herramienta conceptual de la teoría queer es la deconstrucción, entendida como una praxis teórica y práctica, cuya sola posibilidad se entiende como suficientemente probatoria de que toda identidad es contingente e inestable y, por lo mismo, que toda identidad es una no-identidad. En línea con el anti-esencialismo de principios de los 90, la teoría queer cuestiona la pretendida identidad de los sujetos, tanto la de los heterosexuales, como la de los gays y las lesbianas, que en particular en las campañas sobre el SIDA de los años 80 habían generado una fuerte política identitaria. Factores como la etnicidad, la clase o la religión colaboran además a desestabilizar la idea de una identidad definida en razón de una sola variable. Tampoco la diferencia sexual puede definir una identidad masculina-femenina, pues es una más de las múltiples diferencias que atraviesan a los sujetos y los construyen transversalmente en tanto que ejes de poder.

La crítica a la política de la identidad se retrotrae a la «historificación» de los géneros y de la sexualidad de raíz foucaultiana y encuentra su eco en las tesis de Judith Butler, quien habla de la performatividad subversiva que desplace los roles de género clásicos y heterocentrados, por cuanto tanto el género como el sexo son, como decíamos, construidos: « $\mathrm{Si}$ se refuta el carácter invariable del sexo, quizás esta construcción denominada «sexo» esté tan culturalmente construida como el género; de hecho, quizá fue siempre género, con el resultado de que la distinción entre sexo y género no existe como tal» (Butler, 2007, 55).

Para la teoría queer, el binarismo sexual encontró su discurso biológico al establecer las hormonas -estrógenos, progesterona, testosterona- como masculinas o femeninas. Con ello, se naturaliza aquello que sólo es producto de la clasificación cultural. Anne Fausto-Sterling puso de manifiesto cómo la materialidad corporal es producto social, de modo que las posibilidades biológicas iniciales en niños y niñas son las mismas y sólo el discurso sociosimbólico explica las supuestas diferencias entre ellos (Fausto-Sterling, 1994). Por tanto, la materialidad corporal que se presenta en forma de binarismo sexual no es una esencia presocial, sino que se constituye precisamente por la categorización social y cultural.

La teoría queer, a partir de estos supuestos, es lógicamente crítica con el saber tradicional, con la pretendida objetividad y universalidad de las ciencias sociales y empíricas. Pero también es crítica con el paradigma de pensamiento feminista que sigue inmerso en la concepción heterosexual a la hora de analizar las relaciones de género. Esta es la posición que mantuvo Monique Wittig, quien ya en los años ochenta alertó sobre la heteronormatividad que construye y hace pasar por natural el dualismo de género en virtud de una «straight mind» (mente recta) , que también produce la idea de un género femenino como resultado de tal normatividad: «Lo que hace a una mujer es una relación social específica con un hombre, una relación que previamente habíamos denominado servidumbre, una relación que implica una obligación personal y física, así como una obligación económica» (Wittig, 1992, 20).) Además de Wittig, a quien Butler retoma y desarrolla, otros referentes relevantes de la teoría queer son David Halperlin (Halperlin, 1985), que analiza la historia de la homosexualidad; Teresa de Lauretis (de Lauretis, 1991) que puso el término queer en circulación; y Gayle Rubin (Rubin, 1975), quien es antecedente directo en la indagación de cómo funciona el sistema género/sexo.

Pero, sin duda, hablar de teoría queer es hablar de la filósofa norteamericana Judith Butler; y, más en concreto, de su publicación, que ya hemos recogido aquí, titulada Gender Trouble. Feminism and the Subversion of Identity. Incorporando la categoría de género en la elaboración teórica del post-estructuralismo, Butler apuesta por desestabilizar las identidades 
sexuales y de género y apunta cómo estas componen la «matriz heterosexual», concepto que viene a significar una disposición social y cultural o, como lo expresaría Foucault, un «dispositivo discursivo». Este dispositivo es multidimensional, ya que incorpora la dimensión del cuerpo sexual, la de los roles sociales de género y la propia del deseo. La «matriz heterosexual» no es otra cosa que la inter-relación entre estas tres dimensiones, a la vez que la exigencia normativa de que de que todas ellas se ajusten a esa matriz.

El resultado es que los seres humanos se van a dividir en dos géneros diversos entre sí, de manera que deviene producto cultural lo que se presenta como orden natural. Y de este modo el orden, simbólico y real, es categorizado en términos de heterosexualidad. Atravesar ese orden simbólico y real, detectarlo y sacar a la luz su carga normativa es ya parte del trabajo de deconstrucción que la teoría queer se propone. Por ejemplo, para Butler está claro que la categoría «mujer», que el feminismo ha venido utilizando, remite a una identidad que es meramente construida y que además ha sido excluyente de otras identidades. Por eso afirma que tal categoría ha de ser cuestionada, pues se trata no de una mera expresión descriptiva -como pretende-, sino de una categoría excluyente y, por tanto, represiva que se quiere hacer pasar por natural; $y$, con ello, se trata también de problematizar esta categoría como sujeto político del feminismo: «En su mayoría, la teoría feminista ha asumido que existe cierta identidad, entendida mediante la categoría de las mujeres, que no sólo introduce los intereses y los objetivos feministas dentro del discurso, sino que se convierte en el sujeto para el cual se procura la representación política. Recientemente, esta concepción dominante sobre la relación entre teoría feminista y política se ha puesto en tela de juicio desde dentro del discurso feminista. El tema de las mujeres ya no se ve en términos estables o constantes. Hay numerosas obras que cuestionan la viabilidad del "sujeto" como el candidato principal de la representación o, incluso, de la liberación, pero además hay muy poco acuerdo acerca de qué es, o debería ser, la categoría de "las mujeres"» (Butler, 2007, 46).

Butler no está sola en su camino teórico: tiene detrás el pensamiento feminista de los años 70 y 80 del siglo XX, que ya había teorizado sobre la triada conceptual de sexo-génerodeseo. La visión claramente constructivista y también anti-esencialista de este pensamiento está sin duda entre las herencias directas de Butler. Pero ella da un paso más: ninguna de estas tres categorías son datos auto-evidentes y esenciales, sino el efecto performativo de la puesta en acto de las normas de la matriz heterosexual. No hay, por tanto, identidad genérica estable, sino que esta se hace. Y se hace en la repetición discursiva y encarnada de las normas de género. La repetición es de por sí inestable, y por ello mismo produce errores y subversiones de la norma que pone en acto.

Butler se interesa en particular por las fisuras en la reproducción de la matriz heterosexual, porque en estos fallos del acto performativo se da la ocasión y se posibilita el desorden de género, que pone en peligro el orden heterosexual mismo. Estas realizaciones fallidas abren la puerta a la proliferación de géneros, y Butler se va a interesar especialmente por las minorías sexuales, tomando la performance de las drag queen como ejemplificación para «desmantelar el supuesto de que el género es un concepto unitario que remite a un ser coherente y natural» (Burgos, 2008, 197). Si algo no concuerda con el cuerpo al que se le asigna un sexo/género, o si el comportamiento no se ajusta a los roles esperados se da la transgresión de la norma de género que se quiere imponer como orden obligatorio y que ejerce su represión sobre toda transgresión. Hay, pues, para Butler una posibilidad de agen- 
cia en tanto en cuanto hay repetición de la norma y, con ello, y a la vez, transgresión de la misma: «No hay ningún sujeto anterior a sus construcciones ni el sujeto está determinado por tales construcciones; siempre es el nexo, el no-espacio de una colisión cultural, en la que la demanda de resignificar o repetir los términos mismos que constituyen el 'nosotros' no puede rechazarse sumariamente, pero donde tampoco puede acatarse en estricta obediencia. El espacio de esta ambivalencia es lo que da la posibilidad de reelaborar los términos mismos mediante los cuales se da o no la sujeción» (Butler, 2002, 183).

Frente a la idea de un sujeto fuerte y constituyente, que para Butler ya ha sido deconstruida desde el discurso post-estructuralista, ella aboga por un sujeto en coalición, que traspasa las fronteras convencionales de la identidad y que tiene como meta política la subversión de las normas de género. Se trata de un sujeto que performa identidades diversas: sexuales, de género, étnicas, culturales y sociales. Por ello, para Butler el feminismo ya no puede seguir siendo una perspectiva ni única ni prioritaria desde el punto de vista teórico y político, sino que ha de aliarse con las causas de los transexuales e intersexuales, gays y lesbianas anti-esencialistas: con todas las formas de sexualidad alternativas. De este modo, el feminismo deviene por deconstrucción también en otra cosa, en una suerte de postfeminismo que se articula como teoría y política queer.

\section{Teoría queer en el contexto español}

En España aparecen en los noventas grupos activista queer, como La radical Gai o el grupo LSD, que fermentan a mediados de esos años en los estudios académicos y dan lugar a actividades y publicaciones diversas dentro de ese marco teórico (Sáez, 2008, 11-14). Como ocurre en Estados Unidos (con grupos como ACT UP), también en el estado español la crisis del sida «puso de manifiesto que la construcción social de los cuerpos, su represión, el ejercicio del poder, la homofobia, la exclusión social, el colonialismo, la lucha de clases, el sistema de sexo y género, el heterocentrismo, etc., son fenómenos que se comunica entre sí, que se producen por medio de un conjunto de tecnologías complejas, y que la reacción o la resistencia a esos poderes exige asimismo estrategias articuladas que tengan en cuenta numerosos criterios: raza, clase social, género, inmigración, enfermedad,...criterios fundamentales de lucha que ponen sobre la mesa las multitudes queer» (Sáez, 2005, 69).

Estas «multitudes queer» no hacen referencia a un sentido cuantitativo, sino a la transversalidad que las caracteriza, por cuanto identidades diversas vienen a cruzarse en una misma resistencia al orden heternormativo establecido. Casi todos los teóricos queer hablan además de la crisis del feminismo como uno de los caldos de cultivo de esa teoría, En particular, las reclamaciones de las mujeres lesbianas y de las mujeres negras o chicanas a partir de los años ochenta, que no se sienten representadas en un feminismo hegemónico blanco, occidental y de clase media, abren la puerta a la teorización de otros ejes de dominación que inciden en «el reconocimiento de la fragilidad de la identidad y de los complicados procesos que se producen en la formación de la identidad» (López Penedo, 2008, 104). La impugnación de un feminismo que reproduce el orden heterosexual, blanco y excluyente es asumida por escritoras y pensadoras como Adrienne Rich, Audre Lorde, Monique Wittig, Gloria Anzaldúa, Cherrie Moraga (Sáez, 2005, 70-71); y, a partir de aquí, se demanda un análisis transversal que incorpore variables como la raza, la clase o la orientación sexual, posibilitando 
así una visión inclusiva de las minorías olvidadas en el discurso feminista. Estas posiciones críticas impactan en el contexto español a partir de los años noventa, abonando igualmente el terreno para la teoría queer a partir de esos años.

La mayoría de los estudios sobre y desde la teoría queer que se han venido realizando en España abordan las raíces del post-estructuralismo de Foucault, Deleuze, Guattari o Derrida (Sáez, 2008, 61-95; Córdoba, 2005, 29-33); intentan clarificar qué es eso de la teoría queer o del propio término queer (Ceballos Muñoz, 2005, 165-177; López Penedo, 2008, 17-39; Carrascosa, 2005, 179-180); dan testimonio de las prácticas y el activismo queer en nuestro estado (Trujillo Barbadillo, 2005, 29-449); plantean la construcción de una subjetividad a partir de prácticas sexuales sado-masoquistas (Martínez Pulet, 2005, 213-228), o de la «contrasexualidad» (Preciado, 2011); indagan las relaciones entre el pensamiento queer y el psicoanálisis (Sáez, 2008); presentan este pensamiento desde una propuesta de sistematización del mismo (López Penedo, 2008); analizan sus producciones culturales (Nabal, 2005, 229-238; Soto, 2005, 239-257); entre otros intereses que cabe encontrar en el panorama y lo temas que abordan los estudios y las publicaciones queer en nuestro entorno.

La teoría queer en el estado español también se reclama, como toda la teoría queer, heredera del pensamiento post-estructuralista, entendiendo por tal «nuevas líneas de pensamiento y de crítica social y política» que se traducen en «un conjunto de textos y autores que se suelen agrupar un tanto arbitrariamente bajo la categoría de «post-estructralismo»» (Sáez, 2008, 62). Probablemente entre los muchos factores que comparecen a la hora de dar cuenta del surgimiento de la teoría queer, estas « nuevas líneas» constituyan uno de los más relevantes. Dicho de una manera muy esquemática, el post-estructuralismo pone en solfa el sujeto auto-constituyente ilustrado y sus pretensiones de conocimiento. Ya Althusser entendió el sujeto en una dirección contraria al sujeto propio del pensamiento burgués ilustrado: el sujeto es producto del dominio ideológico, de ese poder que lo constituye en la interpelación represiva (Althusser, 1971).

Esta crítica al sujeto de la modernidad se radicaliza en el post-estructuralismo, entendiendo por tal en términos muy amplios a pensadores que -como Foucault, Derrida o Deleuze (Sáez, 2008, 65-91)- enfrentan al mismo un pensamiento netamente anti-esencialista que imposibilita designar una estructura identitaria como principio de orden y de verdad. Al renunciar a la idea de un ser verdadero o auténtico, el pensamiento post-estructuralista deconstruirá, en términos derrideanos, el binarismo jerárquico entre original y copia: toda copia remite a otra copia y el original no es otra cosa que la copia misma. Esta tesis postestructuralista será crucial en el pensamiento del feminismo de Judith Butler y, desde ahí, en los planteamientos de la teoría queer: para el caso del género, no hay original al que remita el juego paródico que lo produce y lo reproduce; se trata de una imitación en sentido originario, detrás de la cual no hay ningún arquetipo o modelo a imitar. Precisamente Butler sería la pensadora encargada de incorporar la categoría de género al análisis post-estructuralista en su libro Gender Trouble, verdadero libro de cabecera de la teoría queer.

En el contexto español la influencia del post-estructuralismo en la teoría queer reclama $\mathrm{La}$ voluntad de saber de Foucault como análisis de referencia, que «abre el espacio para interrogar la sexualidad en su historicidad, en su contingencia como dispositivo histórico propio de la modernidad occidental. Y, de alguna forma, en una mirada retroactiva, podemos decir que es el momento inaugural anticipado de la teoría queer» (Córdoba García, 2005, 29). Pero también 
ha reclamado el concepto de «suplementaridad» de Derrida, que pone en juego la relación por la cual «la heterosexualidad necesita de la homosexualidad para poder articular su propia definición» (López Penedo, 2008, 86). Estas y otras influencias son palpables en la teoría queer que, en España, hace valer su deriva del contexto post-estructuralista (Sáez, 2008, 65).

Otra dirección de la teoría queer en nuestro entorno se dirige a clarificar, como dijimos, qué sea eso de la «teoría queer»e, incluso, cómo cabe entender el propio término «queer». La primera en utilizar esta expresión fue Teresa de Lauretis, significando con ello una posición crítica que fuese más radical que los denominados estudios gays o lesbianos (De Lauretis, 1991). A partir de ahí la teoría queer se asocia a temas relacionados con diversas formas de transgresión de las normas de género: interesan las prácticas de los drag kings y los drag queens, las relaciones sado-maso, el esquema relacional butch-femme, el trans-género, etc.

Frente a la dificultad de establecer qué cabe entender por teoría queer ( Mérida Jiménez, 2002,20 ), se ha señalado que los específico de la misma es que «difumina las categorías que permiten la normatividad sexual y difiere de los Estudios de Gays y Lesbianas en que evita el engaño de inventar o referirse siquiera a un tipo de sexualidad ideal, libre, nueva, natural o esencial, demostrando así su comprensión de que la sexualidad es un efecto del discurso, ya que no asume para sí ninguna materialidad específica» (Ceballos Muñoz 2005, 173). Como efectos del discurso, también las categorías de «hombre» $\mathrm{y}$ «mujer» se ponen en entredicho, en tanto en cuanto se rechaza que remitan a ninguna diferencia sexual esencial. Pero quizá haya que objetar aquí que, para un pensamiento crítico-feminista, el carácter construido de tales categorías no elimina su utilización para designar e impugnar el orden socio-simbólico imperante. Volveremos sobre esta objeción a la hora de abordar cómo leer, a nuestro juicio inadecuadamente, el feminismo desde la propuesta queer.

Recoger las prácticas del activismo queer ha sido otro de los puntos de interés de la teoría queer en España. En particular el feminismo que se auto-reivindica en esta dirección ha dado testimonio de sus acciones vinculadas a la idea de que «lo queer no supone tanto una identidad como una interrogación crítica de las identidades» (Trujillo Barbadillo, 2005, 39). Reclamándose herederas de las tesis de Butler, estas acciones se han encaminado a evidenciar la parodia de género, la performance de las identidades genéricas que ponen de manifiesto las posibilidades de subvertir y desestabilizar el orden pretendidamente natural de la diferencia sexual.

La intervención política en España de grupos queer, como el colectivo LSD, se dirigió en particular a impugnar el poder como poder heteropatriarcal, y a hacer visible una representación distinta del sujeto político: esta nueva representación rompe con las mujeres como sujeto político feminista y pone en el centro un sujeto queer, una «nueva visión del sujeto político, como maricón o bollo subversivos capaces de cuestionar el heterocentrismo dominante, identidades estas concebidas como un contingente en el que las transversales de clase, raza, creencia o cultura eran factores constitutivos de la propia identidad, pero que los alejaba de esa falsa polaridad de homosexual $v s$. heterosexual en las que estaban basadas los grupos de liberación sexual» (Carrascosa y Vila Núñez, 2005, 51); se trata, en fin, de un sujeto que, desafiando la traducción literal y despectiva del término queer como «maricón» o «bollera», se sitúa en «el entrecruzado de las barreras de identificación y el deseo entre géneros, razas, y definiciones sexuales» (Ceballos Muñoz, 2005, 169).

La reivindicación de prácticas sexuales tradicionalmente consideradas perversas o desviadas ha sido también otro de los ejes del discurso queer. Así, la relación de dominación- 
sumisión consentida y pactada en la forma del sado-masoquismo, o relaciones SM, se convierte en un modelo de reivindicación política de la libertad de establecer roles sexuales para la obtención del placer fuera de la normatividad heterosexual: «Frente a la extendida idea de que el SM es ejercicio de violencia, los activistas van a insistir en que se trata de un juego sexual consentido entre adultos. El SM es, fundamentalmente, un juego safe, sane and consensual: hasta tal punto se basa en el respeto y en la confianza que, sin estos ingredientes no habría posibilidad de sesión» (Martínez Pulet, 2005, 223).

La búsqueda de formas alternativas de sexualidad, que contravengan y desafíen las convenciones sexuales, encuentra su máxima expresión en la propuesta queer de una contrasexualidad. Esta es la demanda de la filósofa española Beatriz Preciado en su Manifiesto contrasexual, publicado originalmente en Francia en el año 2000. Entendiendo el sexo como tecnología biopolítica, en la estela foucaultiana, este manifiesto parte de que «los órganos sexuales no existen», por cuanto «son ya el producto de una tecnología sofisticada que prescribe el contexto en el que los órganos adquieren su significación» (Preciado, 2011, 23). Y, a partir de aquí, la autora propone los principios de una sociedad contrasexual, con sus propias prácticas de inversión contrasexual (como la utilización del dildo descrita como «dildotectónica»), destinados a borrar la frontera masculino-femenino y a alumbrar una sociedad contrasexual de cuerpos hablantes (Preciado, 2011, 35). Amén del tono casi de ciencia-ficción de este manifiesto, es de destacar que en él se extraen las consecuencias más radicales de la política queer: se borra la supuesta naturalidad de la distinción entre hombre y mujer, pero también, en línea con Haraway (Haraway, 1996), las fronteras entre sujeto sensible y objeto inanimado, entre organismo y máquina. Si las ciencias siguen perpetuando esos binarismos cartesianos será sólo, para Preciado, porque con ello «refuerzan la estigmatización política de determinados grupos (las mujeres, los no blancos, las queers, los discapacitados, los enfermos, etc.), y permiten impedirles sistemáticamente el acceso a las tecnologías textuales, discursivas, corporales...que los producen y los objetivan» (Preciado, 2011, 157).

También se han dado en nuestro estado intentos de presentar el pensamiento queer desde una sistematización que quiere recorrerlo desde sus abonos teóricos -como el feminismo, el posmodernismo o los estudios culturales-, hasta su inserción dentro de los nuevos movimientos sociales (López Penedo, 2008). Pero lo cierto es que la labor de sistematización de esta dirección es todavía escasa y se limita más bien a publicaciones de carácter colectivo o antologías, que ofrecen una variedad de textos y temáticas diversas antes que una presentación comprehensiva y organizada del mismo. En el ámbito académico, seminarios como el fundado por Paco Vidarte ya en 2003 en la UNED, entre otras iniciativas, abren la vía para introducir la teoría queer en este marco (Sáez, 2008, 13). Desde el denominado feminismo queer se han compilado una serie de trabajos, especialmente orientados a ir más allá del referente estadounidense de la teoría y la práctica queer y centrase en los discursos de nuestro contexto (Grupo de Trabajo Queer, 2005). Pero lo cierto es que en nuestro estado la labor de sistematizar esta orientación está aún por hacer, en particular en lo que se refiere a la historia y las elaboraciones de la teoría queer en España.

Por último, apuntar tan sólo que la teoría queer también analiza la producción cultural, o, por mejor decirlo, los discursos de la misma. Y esta «relectura queer de la cultura» (López Penedo, 2008, 203) ha encontrado eco en nuestro estado: así, se ha abordado una genealogía, quizá imposible, del nuevo cine queer (Nabal, 2005, 229), o se ha elaborado un análisis sobre 
las literaturas queer (Soto, 2005, 239). Esta aproximación a las producciones culturales no está guiada por un canon de análisis queer hecho y cerrado, cosa que resultaría contraria al mismo carácter de este pensamiento. Pero la mirada queer sobre estos discursos se compromete con su revisión y con su reinterpretación en términos identificables para la comunidad queer (como ocurre, por ejemplo, con la labor de la fotógrafa queer por excelencia Della Grace Volcano).

En este somero repaso a los intereses de la teoría queer, particularmente en voces de la misma del estado español, hemos dejado de lado una cuestión fundamental, para recogerla ahora en un tercer momento de estas reflexiones. Se trata del denominado feminismo queer, que se auto-reclama como propuesta (post-) feminista y que gira, sobre todo, en torno al tema de la identidad. A ocuparnos brevemente de esta cuestión dedicaremos unas reflexiones finales, yendo más allá de nuevo de las fronteras del pensamiento queer español, para, si no polemizar, sí al menos cuestionar que con esta teoría se haya abierto la puerta a una orientación que viene a sustituir a la crítica feminista o a significar el momento post- de la misma.

\section{Algunas reflexiones para concluir sobre feminismo y teoría queer}

El pensamiento feminista contemporáneo ha reflexionado sobre la identidad, el sexo, el género, el cuerpo, y ha puesto en cuestión las normas de género que imponen la heteronormatividad obligatoria. La teoría queer recoge esta herencia crítica, pero la vuelve contra el discurso más esencialista del feminismo, aquel que, como el feminismo cultural norteamericano o el pensamiento de la diferencia sexual en Europa, habla de una identidad específicamente femenina, propia y distinta de la masculina. Esta reacción al discurso esencialista es, sin embargo, presentada como una crítica a todo el pensamiento feminista, de manera que, a mi juicio, se confunde una parte con el todo, impugnando la globalidad del discurso feminista en razón de lo que ha constituido sólo una línea, y no la mayoritaria, del mismo.

Casi todos los teóricos queer resaltan la «crisis del feminismo» como una de sus herencias fundamentales (Sáez, 2005, 70-71). Y, al hablar de esta crisis, se refieren a cómo, a partir de los años 80, grupos de mujeres negras, lesbianas, chicanas, etc. denuncian que no están representadas en el feminismo hegemónico. A partir de estos años el feminismo se diversifica y se fragmenta tanto como las propias variables con las que interactúa. Así, hablar de feminismo hoy será hablar de «raza», de etnicidad, de alternativas verdes o ecológicas, de grupos de mujeres negras, chicanas y emigradas, de preferencias sexuales,...Y todo ello compone una red de variables que lógicamente diversifica los intereses de las mujeres según en qué relación se sitúen con cada una de ellas. Pero no hay que confundir un espectro diversificado con una crisis que viniera a significar algo así como el declinar del pensamiento críticofeminista. En todo caso, cabe hablar para esas múltiples orientaciones de un enriquecimiento del feminismo, por el cual este abre su mirada a una pluralidad de realidades.

En cuanto a la tesis de que las categorías de género, «hombre» $\mathrm{y}$ «mujer», son productos histórico-sociales, esta no se inicia, como a veces se pretende, con el pensamiento queer: esta tesis está firmemente arraigada en el feminismo contemporáneo, que interpela dichas categorías, entendidas como sistema género-sexo, en tanto que formas de estructuración de las relaciones desiguales entre los sexos (De Lauretis, 1986, 11). Y de ahí es de donde, directamente, lo hereda Judith Butler en su obra El género en disputa, para invertir el supuesto epistemológico del pensamiento feminista hasta ese momento y señalar que el género no es 
efecto del sexo, sino que, como ella lo entiende, sería justo al revés: «No tendría sentido definir el género como la categoría cultural del sexo, si éste es ya de por sí una categoría dotada de género. No debe ser visto únicamente como la inscripción cultural del significado en un sexo predeterminado (...) como consecuencia, el género no es a la cultura lo que el sexo es a la naturaleza; el género también es el medio discursivo/cultural a través del cual la «naturaleza sexuada» o «un sexo natural» se forma y se establece como«prediscursivo», anterior a la cultura, una superficie políticamente neutral sobre la cual actúa la cultura» (Butler, 2007, 55-56).

En otras palabras, el sexo tiene género. Esta idea tan foucaultiana, por otro lado, de que el sexo ya está culturalmente connotado tiene, para el caso del sexo femenino, ecos precisos en el famoso aserto de Simone de Beauvoir según el cual no se nace mujer, se llega a serlo. En este caso, ese llegar a ser se entiende en Butler como una permanente construcción, como una reiterada performatividad por la que «el discurso produce los efectos que nombra» (Butler, 2010, 18). De manera que no hay nada así como el sujeto «mujer», que habrá que deconstruir como identidad homogénea (Izquierdo, 2001, 10-12).

Del fin de esa «identidad homogénea» habla también Chantal Mouffe, cuando escribe que ya no tenemos tal cosa, que se opondría a la identidad homogénea «varón», sino que lo que hay es una multiplicidad de relaciones sociales en las cuales la diferencia sexual está construida siempre de muy diversos modos, y donde «la lucha en contra de la subordinación tiene que plantearse de formas específicas y diferenciales» (Mouffe, 1999, 112). Este pensar el fin de las identidades homogéneas en razón del sexo asignado está en línea con las tesis foucaultianas de la emergencia de la sexualidad, con la modernidad burguesa, como un campo social que conforma una scientia sexualis orientada a reglamentar y clasificar como patológicas las conductas sexuales que no se ajustan a la finalidad reproductiva (Foucault, 1995, 48). Por tanto, la concepción de la sexualidad como constructo histórico-social está ya en Foucault y, también, en el pensamiento feminista contemporáneo a él.

Pero reclamar a partir de ahí el mero reconocimiento cultural, como a juicio de Fraser ocurre con la reclamación queer de las sexualidades no normativas (Fraser, 1997, 29), es ir contra la propia tradición feminista en cuanto reivindicación redistributiva. Para esta filósofa, el feminismo tiene que aunar las reclamaciones de una justicia de la redistribución de los recursos y riquezas con una demanda del reconocimiento de las diferencias y, sólo desde ahí, sería posible hablar de feminismo como un proyecto ético-político de transformación social. Por tanto, centrar el foco crítico en el reconocimiento de las reclamaciones de libertad sexual, como las reclamaciones queer, no será suficiente para hablar de una teoría feminista o post-feminista, que no puede limitarse a este único polo de atención.

Una observación crítica será que «La Teoría queer es, sin lugar a dudas, como toda producción social, heredera de su tiempo. Hija de la postmodernidad, ha generado una serie de discursos que reflejan y, a la vez refuerzan, los lugares comunes de la ideología neoliberal que ha dominado en las tres últimas décadas» (López Penedo, 2008, 247). También desde aquí, el pensamiento crítico feminista viene a diferenciarse de la teoría queer: hijo bastardo de la Ilustración, el feminismo tiene una tradición de más de tres siglos, ha configurado una genealogía propia e, imbricado con los discursos propios de cada momento histórico, ha generado sus propias señas de identidad. Por tanto, aunque la teoría queer tenga indudablemente raíces en el pensamiento feminista contemporáneo sobre el sexo y el género, no puede venir a suplantar esa tradición de pensamiento que se retrotrae mucho más atrás de las «tres últimas décadas». 
Una última consideración nos lleva hasta la idea de un sujeto feminista. Pensar hoy desde el feminismo el sujeto pasa por admitir que la identidad «mujeres», más allá de toda esencialización, cumple el papel de una identidad estratégica: se trataría de «asumir una materialidad específica pero también una identidad simulada y múltiple, conjugar la fragmentación con la pluralidad: ser varias cuando se nos quiera adscribir a una identidad preestablecida y ajena, una y definida cuando se nos quiere anular» (Rodríguez Magda, 1999, 138). Esta identidad estratégica puede y debe coaligarse con otros sujetos que, como los homosexuales, las lesbianas, los transexuales o los transgénero, están embarcados también en una lucha contra el orden patriarcal heteronormativo. Pero que se dé una eventual coalición con los mismos no hace del feminismo una posición que venga a disolverse en esas posiciones de sujeto reivindicadas por la teoría queer. En un mundo en proceso de globalización, la realidad material de las condiciones de vida de muchas mujeres exige todavía pensar desde el feminismo un proyecto de emancipación social y personal. Y para ese proyecto se necesita todavía un sujeto, un «sujeto verosímil», porque «el problema político real es el de proponer a las mujeres en nuestras sociedades complejas multiculturales objetivos políticos comunes que atraviesen todos los referentes de identidad que las constituyen» (Amorós, 2005, 231). Desde aquí, el feminismo sigue siendo comprendido como una posición política radical y autosuficiente, un discurso crítico con lo que todavía no es ni mucho menos calificable de post-patriarcado en nuestro mundo. Y sus señas de identidad no pueden venir a confundirse, por tanto, con ninguna otra posición por mucho que esta se auto-reclame como post-feminista.

\section{Referencias bibliográficas}

Althusser, L. (1971), Lenin and Philosophy and Other Essays, Monthly Review Press.

Amorós, C. (1991), Hacia una crítica de la razón patriarcal, Barcelona, Anthropos.

Amorós, C. (2005), La gran diferencia y sus pequeñas consecuencias, Madrid, Cátedra.

Butler, J. (2007), El género en disputa: el feminismo y la subversión de la identidad, Barcelona, Paidós.

Butler, J. (2010), Cuerpos que importan: sobre los límites materiales y discursivos del «sexo», Buenos Aires: Paidós.

Burgos, E. (2008), Qué cuenta como una vida. La pregunta por la libertad en Judith Butler. Madrid, A. Machado Libros.

Carrascosa, S. (2005), «¿Qué es queer?», en: D. Córdoba, J. Sáez y P. Vidarte (eds): Teoría queer. Políticas bolleras, maricas, trans, mestizas, Madrid, editorial Egales, pp.179-180.

Carrascosa, S. y Vila Núñez, F., «Geografías víricas: hábitats e imágenes de coaliciones y resistencias», en: Grupo de Trabajo Queer (eds.), El eje del mal es heterosexual. Figuraciones, movimientos y prácticas feministas queer, Madrid, Traficantes de Sueños, pp. 48-58.

Ceballos Muñoz, A., «Teoría rarita», en: D. Córdoba, J. Sáez y P. Vidarte (eds), Teoría queer. Políticas bolleras, maricas trans, mestizas, Madrid, editorial Egales, pp. 165-177.

Córdoba García, David (2005), «Teoría queer: reflexiones sobre sexo, sexualidad e identidad. Hacia una politización de la sexualidad», en: D. Córdoba, J. Sáez y P. Vidarte (eds), Teoría queer. Políticas bolleras, maricas trans, mestizas, Madrid, editorial Egales, pp. 21-66.

De Lauretis, T. (1991), «Queer Theoyy: Lesbian and gay Sexualities», Differences: A Journal of Feminist Cultural Studies 3, 2 (Indianápolis), Indiana University Press, pp. iii-xviii. 
Fausto-Sterling, A. (1994, reed.)., Miths of gender: Biological theories about women and men, New York, BasicBooks.

Fraser, N.(1997), Iustitia Interrupta: reflexiones críticas desde la posición "postsocialista», Santa Fé de Bogotá, Siglo del Hombre Editores.

Foucault, M. (1995), Historia de la sexualidad 1. La voluntad de saber, Madrid, Siglo XXI.

Grupo de Trabajo Queer (2005), El eje del mal es heterosexual. Figuraciones, movimientos y prácticas feministas queer, Madrid, Traficantes de Sueños.

Halperin, D. (1985), Saint Foucault-Towards a Gay Hagiography, Nueva York, Oxford University Press.

Haraway, D.J. (1996): Ciencia, cyborgs y mujeres, Madrid, Cátedra.

Izquierdo, M. J. (2001), Sin vuelta de hoja. Sexismo: poder, placer y trabajo, Bilbao, ediciones Bellaterra.

Llamas, R. (1998), Teoría torcida, Madrid, Siglo XXI.

López Penedo, S.: El laberinto queer. La identidad en tiempos de neoliberalismo, Madrid, editorial Egales, 2008.

Martínez Pulet, J.M. (2005), «La construcción de una subjetividad perversa: el SM como metáfora política y sexual», en: D. Córdoba, J. Sáez y P. Vidarte (eds), Teoría queer. Políticas bolleras, maricas, trans, mestizas, Madrid, editorial Egales, pp. 213-228.

Mérida Jiménez, R. (ed.) (2002), Sexualidades transgresoras. Una antología de estudios queer, Barcelona, Icaria.

Mouffe, C. (1999), El retorno de lo político. Comunidad, ciudadanía, pluralismo y democracia radical, Buenos Aires, Paidós

Nabal, E. (2005), «La hora de los malditos. Hacia una genealogía imposible de algo llamado new queer cinema», en: D. Córdoba, J. Sáez y P. Vidarte (eds), Teoría queer. Políticas bolleras, maricas, trans, mestizas, Madrid, editorial Egales, pp. 229-238.

Preciado, B. (2011), Manifiesto contrasexual, Barcelona, Anagrama.

Rodríguez Magda, R. M., Foucault y la genealogía de los sexos, Anthropos, Barcelona, 1999

Rubin, G. (1975), «The Traffic in Women», en: R.R. Reiter (ed.): Toward an Anthropology of Women, Nueva York, Monthly Review Press.

Sáez, J.: «El contexto sociopolítico de surgimiento de la teoría queer. De la crisis del sida a Foucault», en: D. Córdoba, J. Sáez y P. Vidarte (eds), Teoría queer. Políticas bolleras, maricas trans, mestizas, Madrid, editorial Egales, pp. 67-76.

Sáez, J., (2008), Teoría queer y psicoanálisis, Madrid, Ed. Síntesis.

Sedgwick, E . K. (1990), Epistemology of the Closet, Berkeley, University of California Press, 1990.

Soto, M. (2005), «Literaturas queer, Esa lección olvidada de Barrio Sésamo», en: D. Córdoba, J. Sáez y P. Vidarte (eds), Teoría queer. Políticas bolleras, maricas trans, mestizas, Madrid, editorial Egales, pp. 239-257.

Trujillo Barbadillo, G. (2005), «Desde los márgenes. Prácticas y representaciones de los grupos queer en el Estado español», en: Grupo de Trabajo Queer (eds.), El eje del mal es heterosexual. Figuraciones, movimientos y prácticas feministas queer, Madrid, Traficantes de Sueños, pp. 29-44.

Warner, M. (ed.) (1993), Fear of a Queer Planet. Queer Politics and Social Theory, Minneapolis, University of Minnesota Press.

Wittig, M. (1992), The Straight Mind and Other Essays, Boston, Beacon Press. 